\title{
Anti-adhesion and Anti-biofilm Potential of Organosilane Nanoparticles against Foodborne Pathogens
}

\author{
Eleni N. Gkana1, Agapi I. Doulgeraki1,2*, Nikos G. Chorianopoulos ${ }^{2 *}$ and \\ George-John E. Nychas ${ }^{1}$
}

\begin{abstract}
1 Laboratory of Microbiology and Biotechnology of Foods, Department of Food Science and Human Nutrition, Faculty of Foods, Biotechnology and Development, Agricultural University of Athens, Athens, Greece, ${ }^{2}$ Institute of Technology of Agricultural Products, Hellenic Agricultural Organization-DEMETER, Athens, Greece
\end{abstract}

OPEN ACCESS

Edited by:

Joaquin Bautista-Gallego, Instituto de la Grasa (CSIC), Spain

Reviewed by: Lucilla lacumin, University of Udine, Italy Anca loana Nicolau, Dunarea de Jos University, Romania Antonio Benítez Cabello, Consejo Superior de Investigaciones Cientificas, Spain

*Correspondence: Nikos G. Chorianopoulos nchorian@nagref.gr Agapi I. Doulgeraki adoulgeraki@aua.gr

Specialty section: This article was submitted to

Food Microbiology, a section of the journal

Frontiers in Microbiology

Received: 11 March 2017 Accepted: 27 June 2017 Published: 11 July 2017

Citation:

Gkana EN, Doulgeraki Al,

Chorianopoulos NG and

Nychas G-JE (2017) Anti-adhesion

and Anti-biofilm Potential

of Organosilane Nanoparticles against

Foodborne Pathogens.

Front. Microbiol. 8:1295.

doi: 10.3389/fmicb.2017.01295
Nowadays, modification of surfaces by nanoparticulate coatings is a simple process that may have applications in reducing the prevalence of bacterial cells both on medical devices and food processing surfaces. To this direction, biofilm biological cycle of Salmonella Typhimurium, Listeria monocytogenes, Escherichia coli O157:H7, Staphylococcus aureus, and Yersinia enterocolitica on stainless steel and glass surfaces, with or without nanocoating was monitored. To achieve this, four different commercial nanoparticle compounds (two for each surface) based on organofunctionalized silanes were selected. In total 10 strains of above species (two for each species) were selected to form biofilms on modified or not, stainless steel or glass surfaces, incubated at $37^{\circ} \mathrm{C}$ for $72 \mathrm{~h}$. Biofilm population was enumerated by bead vortexing-plate counting method at four time intervals (3, 24, 48, and $72 \mathrm{~h}$ ). Organosilane based products seemed to affect bacterial attachment on the inert surfaces and/or subsequent biofilm formation, but it was highly dependent on the species and material of surfaces involved. Specifically, reduced bacterial adhesion (at $3 \mathrm{~h}$ ) of Salmonella and E. coli was observed $(P<0.05)$ in nanocoating glass surfaces in comparison with the control ones. Moreover, fewer Salmonella and Yersinia biofilm cells were enumerated on stainless steel coupons coated with organosilanes, than on non-coated surfaces at $24 \mathrm{~h}$ $(P<0.05)$. This study gives an insight to the efficacy of organosilanes based coatings against biofilm formation of foodborne pathogens, however, further studies are needed to better understand the impact of surface modification and the underlying mechanisms which are involved in this phenomenon.

Keywords: organosilanes, nanoparticles, biofilms, foodborne pathogens, anti-adhesion

\section{INTRODUCTION}

During the last decades, it has become increasingly clear that biofilms are the predominant mode of bacterial growth in most of the natural environments (Lindsay and von Holy, 2006; Giaouris et al., 2013). Biofilm formation consists of at least two stages of development: the adherence of cells to an inert surface which may occur very rapidly and the formation of multilayered cell clusters 
surrounded by exopolysaccharides produced by bacteria (Götz, 2002). Initial adhesion process depends on bacterial species, interaction medium and inert surface (Pereni et al., 2006). Biofilm control or eradication occurs a considerable issue for food and medicine sector, since this complex bacterial community is resistant to antimicrobial and disinfectant agents (Hoyle and Costerton, 1991; Finlay and Falkow, 1997; Araújo et al., 2011; Bridier et al., 2011). Regarding the important medical and economic consequences of biofilm formation, the understanding of colonization process would be helpful in the design of surface modifications capable of preventing biofilm formation (PrigentCombaret et al., 1999). Surface properties can be practically modified to reduce bacterial adhesion and further biofouling, which is a principal objective for food industries (Pereni et al., 2006). Surface modification refers to the alteration of physical and chemical properties of an inert substratum (roughness, hydrophobicity, etc.), leading to specific biochemical interactions that prevent bacterial attachment and thus biofilm formation (Kasimanickam et al., 2013).

Following this approach, nanomaterials were proposed as an interventional strategy for the management of biofilm formation due to their high surface area to volume ratio and unique chemical and physical properties (Morones et al., 2005). Nanomaterials were developed for a variety of food applications (food additives, food contact surfaces, food packaging, etc.) and for medical devices (catheter materials, dental acrylics, implants, etc.) (Harris and Graffagnini, 2007; Handford et al., 2014). Due to their small size $(1-100 \mathrm{~nm})$ and their ability to cover much larger surface to volume, they possessed altered physicochemical properties in comparison with larger sized material (Oberdörster et al., 2005; Bouwmeester et al., 2014). Nanoparticles such as $\mathrm{ZnO}$ (Heinlaan et al., 2008), $\mathrm{TiO}_{2}$ (Kim et al., 2003; Adams et al., 2006; Chorianopoulos et al., 2011) $\mathrm{CuO}$ (Heinlaan et al., 2008), and $\mathrm{Al}_{3} \mathrm{O}_{2}$ (Ansari et al., 2013). Compared to the quantum of published reports on physical and chemical properties of nanofilms, only limited information is available on the antibacterial properties of these nanomaterials.

Organo-functional silanes could be potential candidates for surface modifications, as can be used to modify the surface energy or wettability of substrates through the interaction of boundary layers of solids with water, effecting variable degrees of hydrophobicity or hydrophilicity (Mittal, 2009). Monomeric silicon chemicals are known as silanes and when they contain at least one silicon carbon bond (e.g., $\mathrm{Si}-\mathrm{CH}_{3}$ ) are called organosilanes (Kregiel and Niedzielska, 2014). Organofunctional silanes are molecules carrying two different reactive groups on their silicon atom so that they can react with inorganic substrates such as glass and stainless steel and form stable covalent bonds and organic substitution (Thames and Panjnani, 1996; Sepeur, 2008). Several studies have examined the antimicrobial activity of nanoparticulate coatings constituted of silica and organosilanes; however, results retrieved are controversial.

Based on the above, the current study aimed to assess the potential anti-adhesion and anti-biofilm activity of commercial organosilane products applied on stainless steel and glass surfaces against common foodborne pathogens. To achieve this, biofilm biological cycle of Salmonella Typhimurium, Listeria monocytogenes, Escherichia coli O157:H7, Staphylococcus aureus, and Yersinia enterocolitica on stainless steel and glass surfaces, with or without nanocoating was monitored.

\section{MATERIALS AND METHODS}

\section{Bacterial Strains and Inocula Preparation}

All the microorganisms used in this study are presented in Table 1. They consist of two strains of each species, specifically for L. monocytogenes (FMCC B-125, ScottA, serotype 4 b, epidemic strain, human isolate; FMCC B-129, isolated from ready-to-eat frozen meal, minced meat based), $S$. Typhimurium (FMCC B-137, human isolate epidemic; FMCC B-193, isolated from calf bowel), E. coli O157:H7 (FMCC B-15 and FMCC B-16, both isolated from human feces), $S$. aureus [FMCC B-410, methicillin-resistant (MRSA) strain COL, isolated from hospital; FMCC B-135, isolated from human lesions], and Y. enterocolitica (FMCC B-89, CITY 650; FMCC B-90, CITY 844). Before each experiment the stock cultures (frozen at $-80^{\circ} \mathrm{C}$ ) were subcultured twice on $10 \mathrm{ml}$ of Tryptic Soy Broth (TSB, LAB M Limited, Lancashire, United Kingdom) at $37^{\circ} \mathrm{C}$ for 24 and $16 \mathrm{~h}$, respectively (pre-cultures). Cells from exponential phase (16 h) of cultures were collected by centrifugation $(5000 \times g$ for $10 \mathrm{~min}$ at $4^{\circ} \mathrm{C}$ ), washed twice with $1 / 4$ Ringer solution and re-suspended in $1 / 4$ Ringer solution (working cultures) in order to be used as inoculum for biofilm assays.

\section{Biofilm Formation and Quantification on Polystyrene Microplates}

The ability of 10 bacterial strains to form biofilms on polystyrene (PS) microtiter plates was evaluated by using the method described by Jena et al. (2012) with some adaptations. Working culture of above bacteria was diluted 1:100 into fresh medium TSB. Diluted culture $(20 \mu \mathrm{l})$ was added to the 96 -well plates containing $180 \mu \mathrm{l}$ of TSB. The strains were grown in defined medium (TSB) at $37^{\circ} \mathrm{C}$ for 24 and $48 \mathrm{~h}$ in 96-wells microtiter plates under static conditions.

Following incubation, planktonic bacteria were removed by violently turning upside down the plate to remove growth medium and each well was then washed twice with $200 \mu \mathrm{l}$ 1/4 Ringer solution to remove the loosely attached cells. The remaining adherent bacteria (biofilms) were fixed for $15 \mathrm{~min}$ with $200 \mu \mathrm{l}$ of methanol per well (Stepanović, 2000). The methanol was discarded and the plates were left to air dry in room temperature for $20 \mathrm{~min}$. Biofilm cells were stained with $100 \mu \mathrm{l}$ of $1 \%$ Crystal Violet solution which was added at each well. After washing with $200 \mu \mathrm{l} 1 / 4$ Ringer three times to remove excess stain, the crystal violet was solubilized with $100 \mu$ l ethanol (95\%) for $15 \mathrm{~min}$. Dye absorbance at $575 \mathrm{~nm}$ (A575) was measured using a microtiter plate reader (Sunrise, Tecan, Männedorf, Switzerland). For each strain eight replicates were performed. Regarding the obtained spectrometric measurement of optical densities the strains were classified into the four categories; nonbiofilm producing (OD $<=0.2)$, weakly $(0.2<\mathrm{OD}<=0.4)$, moderately $(0.4<\mathrm{OD}<=0.8)$, and strongly $(0.8<\mathrm{OD})$ 
TABLE 1 | Bacterial species used in this study*.

\begin{tabular}{|c|c|c|c|}
\hline Microorganism & Strain number & Strain characteristics & Origin \\
\hline \multirow[t]{2}{*}{ Listeria monocytogenes } & FMCC B-125 & Scott A, Serotype 4b & Human isolated ${ }^{\mathrm{a}}$ \\
\hline & FMCC B-129 & 21350 & RTE frozen meal - minced meat based \\
\hline \multirow[t]{2}{*}{ Salmonella Typhimurium } & FMCC B-137 & DT 193 Multi-drug resistant & Human isolate epidemic ${ }^{b}$ \\
\hline & FMCC B-193 & $4 / 74$ & Isolated from calf bowel ${ }^{\mathrm{C}}$ \\
\hline \multirow[t]{2}{*}{ E. coli O157:H7 } & FMCC B-15 & NCTC 13125, Verocytoxins negative & Human faeces ${ }^{d}$ \\
\hline & FMCC B-18 & NCTC 13127, Verocytoxins negative & Human faeces ${ }^{d}$ \\
\hline \multirow[t]{2}{*}{ Staphylococcus aureus } & FMCC B-410 & MRSA strain COL & English hospital ${ }^{e}$ \\
\hline & FMCC B-135 & NCBF 1499 & \\
\hline \multirow[t]{2}{*}{ Yersinia enterocolitica } & FMCC B-89 & CITY650 & $\mathrm{INCO}^{\mathrm{a}}$ \\
\hline & FMCC B-90 & CITY844 & $\mathrm{INCO}^{\mathrm{a}}$ \\
\hline
\end{tabular}

* From bacterial culture collection of Laboratory of Microbiology and Biotechnology of Foods (FMCC), Agricultural University of Athens.

a Kindly provided by Dr. E. Smid, ATO-DLO Netherlands.

b Food Microbiology Culture Collection of Agricultural University of Athens.

c Kindly provided by Dr. P. Skandamis.

d Kindly provided by Dr. E. Drosinos.

e Kindly provided by Dr. S. Kathariou, North Carolina State University, United States.

biofilm producing strains according to the method proposed by Stepanović et al. (2004).

\section{Application of Commercial Organosilane Products for Modification of Stainless Steel and Glass Surfaces}

Four organosilane based commercial products for coating of non-absorbing surfaces; two (2) for glass and two (2) for stainless steel, specific to each material surface according to manufacturers, were used. Specifically, three (3) commercial products that were obtained from Liquid Glass Nanotech ${ }^{1}$ with EINECS (European Inventory of Existing Commercial Chemical Substances) registration were used. The active agent was siliconfree siloxane and consists of polymers made of silanes. One (1) organosilane product for glass (OSG1) (Liquid Glass Nanotech for glass and ceramic surfaces, LGN-600-1) and two organosilane products for stainless steel (OSS1, OSS2) (Universal antimicrobial for non-absorbent/hard surfaces, LGN-671-ANTI; Polish for Metals and Plastics for non-absorbent/hard surfaces, LGN-660-1) were used. Moreover one (1) commercial organosilane based product for glass (OSG2) (NANO-SKIN [HOME]) from BFP Hellas Company ${ }^{2}$ was obtained, that is approved by General Chemical State Laboratory of Greece.

All the products were delivered as pump sprays for easy application and were applied following manufacturers' instructions. Briefly, for products OSG1, OSS1, and OSS2 the application consisted of cleaning the surfaces with isopropyl alcohol and then rinsing with deionized water, spraying the coating on surface and evenly distribute the coating with a lint free microfiber cloth across the surface, polish off residue after $30 \mathrm{~min}$ and let the coating seal for at least 12-24 h. NanoSkin product consists of three liquid mixtures (an emulsion and two sprays) which are applied sequentially. Pretreatment with emulsion NANO-SKIN (1) based on a specific composition,

\footnotetext{
${ }^{1}$ https://www.liquidglassnanotech.com/

${ }^{2}$ http://bfphellas.gr/
}

which restores the glass in its initial condition, was required. Then, NANO-SKIN (2) - an alcohol activating solution and NANO-SKIN (3) based on silicon oligomers, both sprayed subsequently to glass surface and spread with microfiber cloth, making gentle circular motions. All the aforementioned products sprayed onto a hard surface form a nano-film by self-organization during evaporation of the solvent (Sepeur, 2008). The film arises from the sol-gel process (Hench and West, 1990; Schmidt, 2006) that involves series of hydrolysis and condensation reactions between organo-functionalized silanes that result in a network of functionalized siloxanes (Nørgaard et al., 2014).

\section{Biofilm Formation on Stainless Steel and Glass Coupons \\ Preparation of Stainless Steel and Glass Surfaces}

Stainless steel is the surface used extensively throughout the food processing industry. On the other hand glass was selected due to its high hydrophilicity and excellent silane effectiveness on this material. In addition, it is well known that significant portion of food deposits is made of glass (e.g., doors and coverings of refrigerators in super markets). Stainless steel is the surface used extensively throughout the food processing industry. Stainless steel (SS) coupons ( 3 by 1 by $0.1 \mathrm{~cm}$, type AISI-304; Halyvourgiki, Inc., Athens, Greece) and glass $(\mathrm{G})$ coupons ( 3 by 1 by $0.1 \mathrm{~cm}$ cut from microscope slides) were initially soaked in acetone (overnight) to remove any manufacturing process debris and grease. Coupons were then washed by soaking overnight at room temperature in a $2 \%(\mathrm{vol} / \mathrm{vol})$ solution of the commercial detergent RBS 35 (Fluka/Life Science Chemilab, S.A.) with shaking, rinsed thoroughly with tap water followed by distilled water and air dried. The coupons were coated by the procedure mentioned above with commercial nano-coatings. Glass and stainless steel coupon without coating were used as control. Finally, cleaned coupons were individually placed in empty glass test tubes (length, $10 \mathrm{~cm}$; diameter, $1.5 \mathrm{~cm}$ ) and autoclaved at $121^{\circ} \mathrm{C}$ for 15 min. 


\section{Biofilm Formation and Enumeration}

Ten strains ( $S$. Typhimurium 137, 193, S. aureus 135, 410, Y. enterocolitica 89, 90, E. coli O157:H7 15, 18, and L. monocytogenes 125,129$)$ were selected to examine biofilm formation on stainless steel and glass surfaces, coated or not with organosilanes. Strains with different isolation origins (i.e., clinical, food, or environment) were selected in an attempt to pursue variability. The study was performed according to the protocol described by Kostaki et al. (2012) with minor modifications. The working cultures were diluted at 1:100 and $0.5 \mathrm{ml}$ was added in $4.5 \mathrm{ml}$ Ringer that contained a stainless steel or glass coupon. For the attachment step, $0.5 \mathrm{ml}$ of each bacterial suspension in $4.5 \mathrm{ml}$ quarter-strength Ringer solution, containing $\mathrm{ca}$. $10^{6} \mathrm{CFU} / \mathrm{ml}$, was poured into each glass test tube containing a sterilized coupon and incubated at $15^{\circ} \mathrm{C}$ for $3 \mathrm{~h}$ under static conditions. This temperature, representative of food industry during non-production hours $\left(15^{\circ} \mathrm{C}\right)$ was incorporated in this study to investigate the adherent properties of abovementioned foodborne pathogens.

Following the attachment step, each coupon was carefully removed from the glass test tube using sterile forceps and individually introduced into a new sterile glass test tube containing $5 \mathrm{ml}$ of TSB and subsequently incubated at $37^{\circ} \mathrm{C}$ for 3 days $(72 \mathrm{~h})$, under static conditions, to allow biofilm development on the coupon, with no growth medium renewal. Each experiment included three replications and sampling was performed at $3,24,48$, and $72 \mathrm{~h}$. A higher temperature $\left(37^{\circ} \mathrm{C}\right)$ of incubation to determine biofilm formation was selected because previous studies have shown that biofilm production is increased when bacteria allowed growing next to or at their optimal temperature (Morton et al., 1998; da Silva Meira et al., 2012; Kadam et al., 2013). Furthermore, it was evaluated that at $37^{\circ} \mathrm{C}$, L. monocytogenes biofilm exhibited a complex system, in terms of cell number and EPS produced, due to advanced state of growth rate. Therefore, this temperature $\left(37^{\circ} \mathrm{C}\right)$ represents the worstcase scenario of biofilm formation in order to determine if there is a potential anti-biofilm activity of organosilanes.

Briefly, each coupon was aseptically removed from the glass test tube and was then rinsed by pipetting twice with $10 \mathrm{ml}$ of quarter-strength Ringer solution (each time). The coupon was transferred to a falcon centrifuge tube containing $6 \mathrm{ml}$ of quarterstrength Ringer solution and 10 sterile glass beads (diameter, $3 \mathrm{~mm}$ ) and then vortexed for $2 \mathrm{~min}$ at maximum speed to detach biofilm cells from the coupon. Detached cells obtained by bead vortexing method (Giaouris and Nychas, 2006) were subsequently enumerated on Tryptone Soy Agar (TSA; Lab M), after 10-fold serial dilutions. Stainless steel and glass surfaces were examined under conventional fluorescence microscope using acridine orange stain to determine the absence of residual biofilm remained on substrate (data not shown).

\section{Data Analysis}

Univariate analysis of Variance (n-way ANOVA) for each stainless steel and glass surfaces was performed to test the main interaction effects of independent factors: (a) three different materials of surfaces (one non-coated and two coated surfaces), (b) five pathogen species (S. Typhimurium. S. aureus,
L. monocytogenes, Y. enterocolitica, and E. coli O157:H7), and (c) four different time points $(3,24,48$, and $72 \mathrm{~h})$ to bacterial attached cells as expressed by $\log \mathrm{CFU} / \mathrm{cm}^{2}$ (dependent). Thus, a $3^{*} 5^{*} 4$ factorial design was constructed and when probability of F-values were less than 0.05 for any independent or combinations of independents, it was concluded that the variable has an effect on the depended. Each experiment was conducted using three replicates for each. The Tukey post hoc test was used to compare the means at the 95\% confidence level. The statistical analysis was conducted using the IBM ${ }^{\circledR}$ SPSS $^{\circledR}$ Statistics for Windows software, Version 22.0 (IBM Corp., Armonk, NY, United States).

\section{RESULTS}

The biofilm forming capacity of five foodborne pathogens at strain level was initially examined in this study by crystal violet method. Briefly, two strains of each pathogen, i.e., S. Typhimurium, L. monocytogenes, E. coli, Y. enterocolitica, and $S$. aureus were left to form biofilm on microtiter plate at $37^{\circ} \mathrm{C}$ to check the strain variability on this phenomenon. In addition, the influence of incubation time, i.e., 24 and $48 \mathrm{~h}$ was estimated. The average optical density (OD575) values were calculated for all tested strains at 24 and $48 \mathrm{~h}$ (Figure 1).

Listeria monocytogenes FMCC-125 was classified as strongly biofilm producing strain, while E. coli O157:H7 FMCC-16 was evaluated as non-biofilm producer. In addition, both strains of S. aureus (FMCC-135, 410), both strains of Y. enterocolitica (FMCC 89, 90) and one strain of E. coli O157:H7 (FMCC-15) was classified as weak biofilm producers. The rest three strains, consisted of both strains of S. Typhimurium (FMCC-137, 193) and a strain of L. monocytogenes were classified as moderate biofilm producers.

The previous tested strains were left to form dual strain biofilm on stainless steel and glass surfaces. In accordance to the previous analyzed results, it was observed that biofilm formation was influenced by the bacterial species and incubation time; however, the effect of surface was also estimated. Briefly, a statistical difference was detected between biofilm formation on glass and stainless steel both at attachment step and formed biofilm (24 and $48 \mathrm{~h}$ ). More specifically, in the case of glass surface the attached and biofilm cell population was found to be lower than on stainless steel surface.

Regarding the observations related to the attachment ability of the pathogens on non-coated glass surfaces (assessment of the population at $3 \mathrm{~h}$ ), it seems that $S$. Typhimurium was attached in higher populations (about $4.32 \log \mathrm{CFU} / \mathrm{cm}^{2}$ ), while S. aureus, E. coli, L. monocytogenes, and Y. enterocolitica were attached at significant lower concentrations (1.6-2.7 log $\mathrm{CFU} / \mathrm{cm}^{2}$ ) (Figure 2; $P<0.05$ ). However, L. monocytogenes and $E$. coli biofilm population was the highest and lowest, respectively $(P<0.05)$, while $S$. Typhimurium, $S$. aureus, and $Y$. enterocolitica biofilm populations were in similar levels at $24 \mathrm{~h}$. Similar observations reported above regarding the data obtained from the microtiter plates assay. After $48 \mathrm{~h}, Y$. enterocolitica biofilm population was significant lower than those of $S$. Typhimurium and L. monocytogenes while $S$. Typhimurium and 


\section{Biobiflm formation on polystyrene microplates}

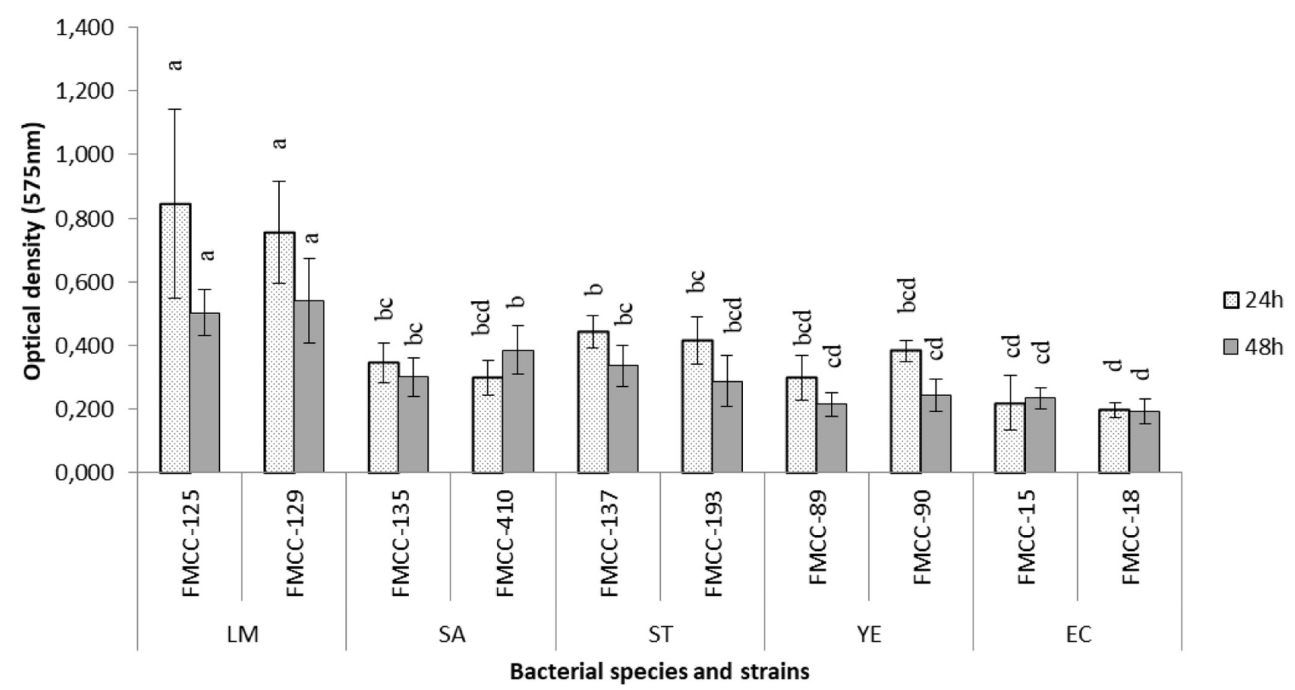

FIGURE 1 | Biofilm formation on polystyrene microtiter plates of different strains after 24 and $48 \mathrm{~h}$ of incubation at $37^{\circ} \mathrm{C}$. Biofilm cells were indirectly quantified by crystal violet staining and absorbance measurements at $575 \mathrm{~nm}$. Bars represent means \pm standard deviations. Different letters at 24 or $48 \mathrm{~h}$ indicate significant differences between biofilm formation of strains $(P<0.05)$.

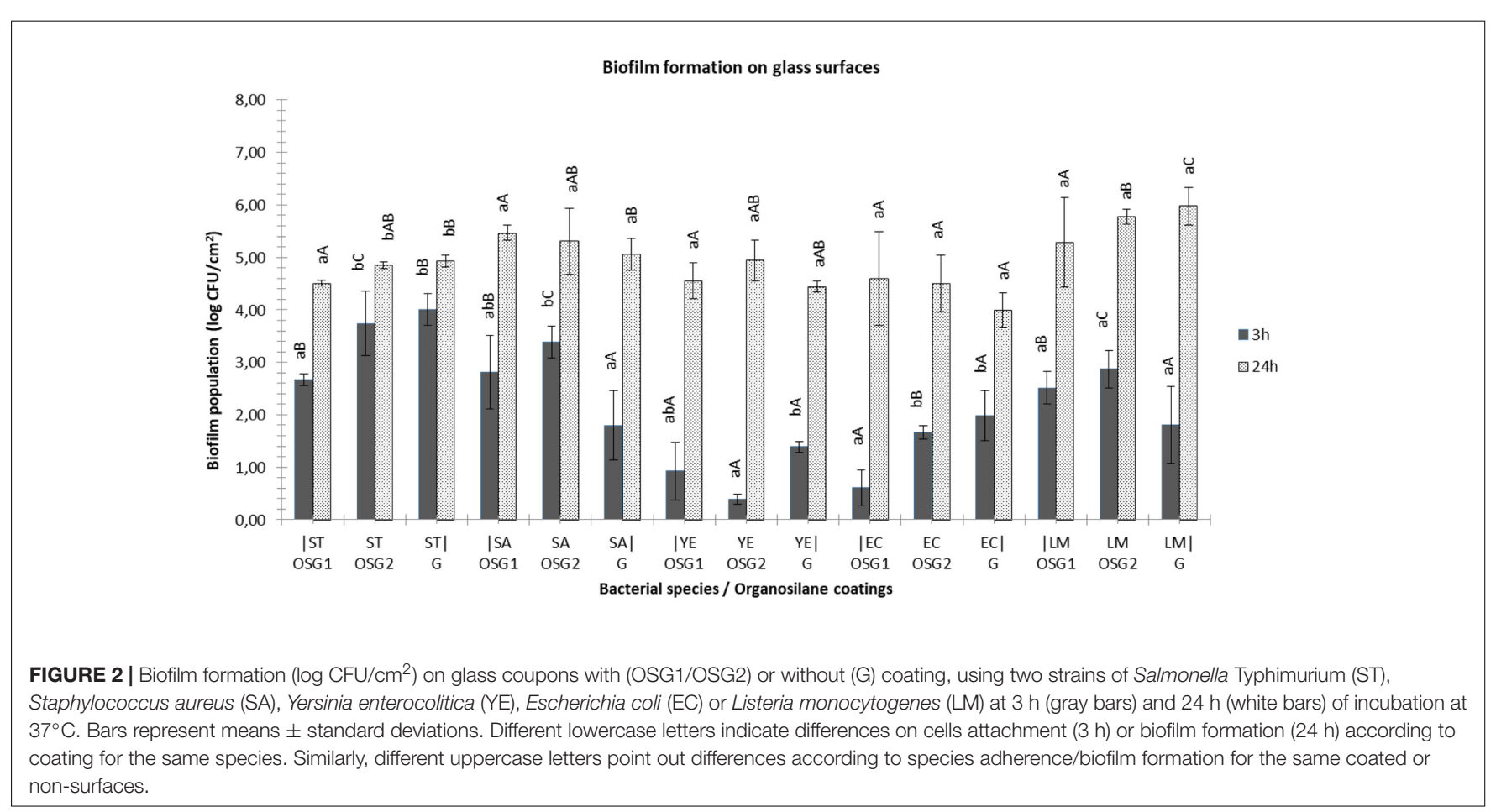

E. coli were found to maintain higher level of sessile cells than Y. enterocolitica, at $72 \mathrm{~h}$.

Biofilm cycles of $S$. Typhimurium and $S$. aureus had similar trend as they reached the higher biofilm formation at $24 \mathrm{~h}$, while a significant reduction of sessile cells was observed at 72 h. E. coli had a different respond as remained throughout incubation period at approximately same numbers of $24 \mathrm{~h}$ biofilm population. Lower numbers of cells were retrieved after $48 \mathrm{~h}$ of incubation as concern L. monocytogenes and Y. enterocolitica compared to biofilm formation of $24 \mathrm{~h}$. At $72 \mathrm{~h}, \mathrm{~L}$. monocytogenes sessile cells were remained at levels estimated at $48 \mathrm{~h}$, while a further reduction was observed for Y. enterocolitica.

Staphylococcus aureus was found to be attached on stainless steel surfaces at a significant higher level compared to glass surfaces. Similar adhesion to glass and stainless steel surfaces and no correlation between materials surface hydrophobicity was 
obtained for all other species. Biofilm formation at $24 \mathrm{~h}$ was found to be significant lower on glass surfaces for $S$. Typhimurium, Y. enterocolitica, and E. coli $(P<0.05)$.

The application of organosilane products was found to affect the adhesion of the pathogens (estimation of population at $3 \mathrm{~h}$ ) on glass surfaces, however, their effect influenced by bacterial species (Figure 2). More specific, product OSG1 reduced adhesion of $S$. Typhimurium and E. coli compared to bare glass surfaces at approximately $1.4 \log \mathrm{CFU} / \mathrm{cm}^{2}$. On the other hand, product OSG2 was found to induce the attachment of $S$. aureus at the level of $1.8 \log \mathrm{CFU} / \mathrm{cm}^{2}$ compared to the non-coated glass coupons. However, it seems that the application of both products affected only the first steps of biofilm formation as no significant differences were observed between coated or not glass surfaces after 24, 48, and $72 \mathrm{~h}$.

On the other hand, significant differences were detected in the case of organosilanes application on stainless steel surfaces compared to bare ones, which highly depended on the bacterial species and time of incubation (Figure 3). Briefly, both OSS1 and OSS2 were able to reduce biofilm formation of $S$. Typhimurium at approximately $0.5 \log \mathrm{CFU} / \mathrm{cm}^{2}$, at $24 \mathrm{~h}(P<0.05)$. Similarly, a reduction of $S$. aureus biofilm cells was observed at the level of $0.8-1.2 \log \mathrm{CFU} / \mathrm{cm}^{2}$ at $48 \mathrm{~h}$. Biofilm formation of $Y$. enterocolitica was also affected after the application of OSS2 as an approximately $1.8 \log \mathrm{CFU} / \mathrm{cm}^{2}$ reduction of population was observed at $24 \mathrm{~h}$.

\section{DISCUSSION}

Physicochemical properties of inert substratum and bacterium cell surface are known to have impact on bacterial attachment and biofilm formation, however, the exact correlation with discrete characteristics is difficult as the system is very complex. Hydrophobicity of surfaces has been reported as an important factor affecting the attachment of bacteria on surfaces. Specifically hydrophobicity seems to decrease the adhesion of microorganisms on inert surfaces (van Loosdrecht et al., 1987; Dickson and Daniels, 1991; Bonsaglia et al., 2014) and in the same time increase the detachment of sessile cells (Pereni et al., 2006). Stainless steel is considered a hydrophobic material (Lafuma and Quéré, 2003), while glass a hydrophilic material (Robert et al., 2001). Modification of surfaces with organosilanes usually increases the hydrophobic qualities and low surface free energy of native surfaces (Kregiel and Niedzielska, 2014).

Regarding the present results organosilanes found to eliminate adherence of $S$. Typhimurium and $E$. coli on modified glass surfaces, but this effect was not evident on stainless steel surfaces. A considerable alteration on physical properties of glass surfaces from hydrophilic to hydrophobic may be the reason of the anti-adherent properties observed. In addition, low surface energy chemistry and nano-textured morphology of the coating (homogeneity of the organosilane layer on glass surfaces) could also result in reduced protein adsorption and inhibition of bacterial attachment (Chen et al., 2013).

Significant reductions on biofilm formation ( 24 and $48 \mathrm{~h}$ ) were pointed out for $S$. aureus, S. Typhimurium, and Y. enterocolitica on modified with organosilanes stainless steel surfaces as compared to their respective controls. A positive correlation between substratum hydrophobicity and the detachment of adherent biofilm was established by other studies. According to this approach, bacteria attached to hydrophobic materials were more easily removed from them (Harkes et al., 1992; Reid et al., 1993; Eginton et al., 1995; Bos et al., 2000; GómezSuárez et al., 2001). On the other hand, S. aureus found to attach more effectively on stainless steel surfaces in comparison

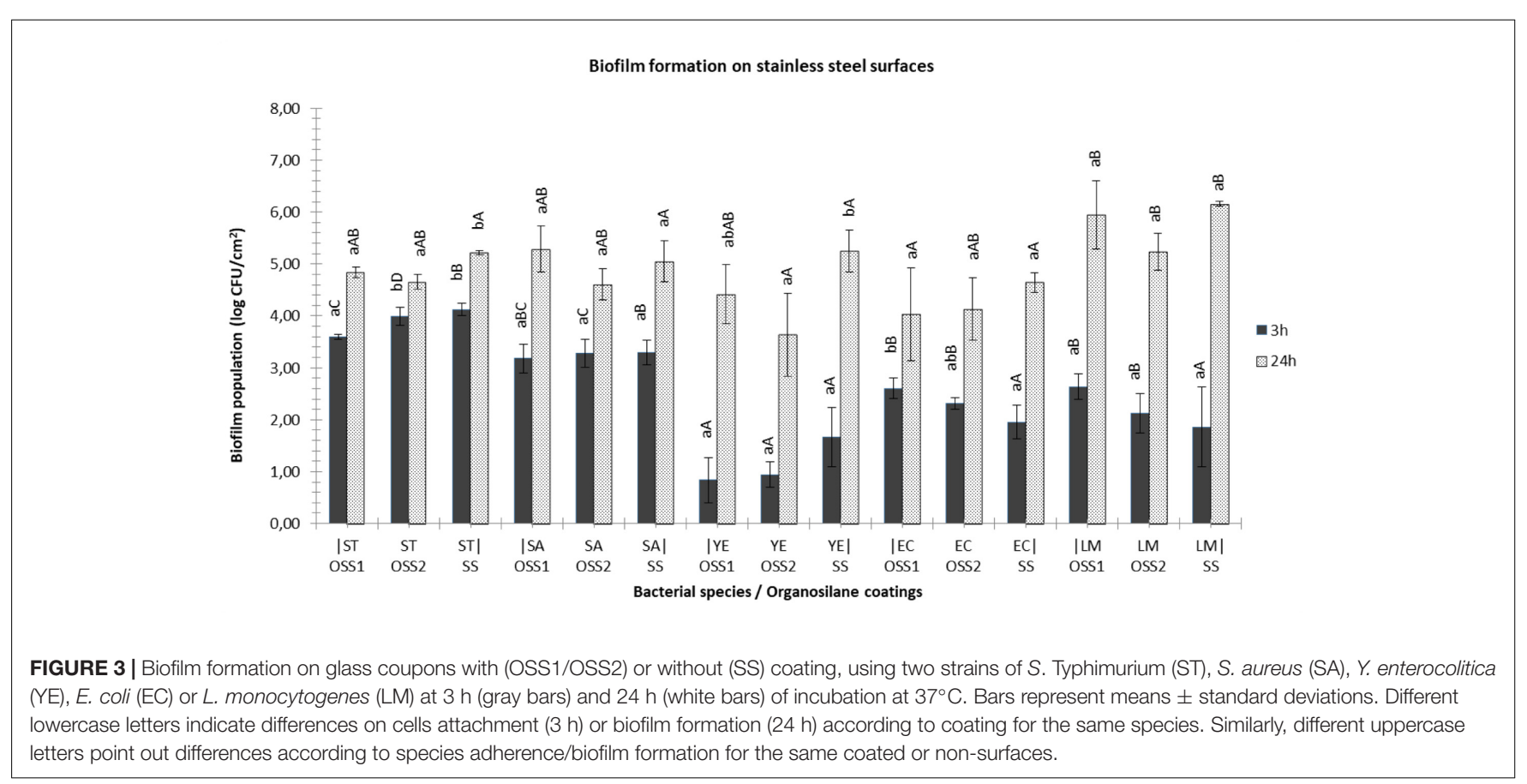


with glass ones, while organosilanes enhance the adherence of bacterium to modified glass surfaces. It seems that a correlation between hydrophobicity and the number of attached cells was resulted. Organosilanes had no effect on eliminating L. monocytogenes attached cells or biofilm formation. No differences were also observed regarding different non-modified glass or stainless steel surfaces. These results are in agreement with other studies, too. Teixeira et al. (2007) claimed that adhesion of L. monocytogenes to abiotic surfaces was not influenced by substratum hydrophobicity and roughness.

Silica nanoparticles have been found to eliminate Candida albicans adhesion and surface associated growth (Cousins et al., 2007). Another study found that concentration of silicon dioxide above $1000 \mathrm{ppm}$ was required to achieve antibacterial activity against Bacillus subtilis and E. coli (Adams et al., 2006). Polyethylene surfaces, following activation by plasma processing and modification with active organosilanes, exhibit anti-adhesive and anti-biofilm properties against Aeromonas hydrophila (Kregiel and Niedzielska, 2014). Glass surfaces coated with hydrophobic silane (alkyl functionalized silane) modified silica nanoparticles exhibited inhibition performance against the growth of E. coli, S. aureus, and Deinococcus geothermalis compared to that of pristine silica nanoparticles (Song et al., 2011). Reduction of $S$. aureus and $P$. aeruginosa adherence on super-hydrophobic surfaces synthesized by fluorinated silica colloids was also demonstrated (Privett et al., 2011). On the other hand, silica nanoparticles against oral pathogenic species of Streptococcus mutans had limited antibacterial effects, using minimum inhibitory concentration assay for planktonic growth, in 96-well microplates (Besinis et al., 2014). Evaluation of two organosilane products applied on high-touch surfaces in patient rooms of a health care facility revealed that no significant residual antimicrobial activity was observed (Boyce et al., 2014).

Numerous previous studies have described the ability of aforementioned foodborne pathogens to attach to various surfaces and form biofilms (Joseph et al., 2001; Stepanović et al., 2004; Kim et al., 2008; Dourou et al., 2011; Oniciuc et al., 2016), with this ability to be depended on the interaction between intrinsic and extrinsic factors such as the bacterial cells, the attachment surface and the surrounding environmental conditions (Giaouris et al., 2014). However, most of these previous studies were performed by constructing singlestrain biofilms, with obtaining results not to be necessarily representative of the bacterial species as whole. Undoubtedly, bacterial strains, even the ones belonging to the same species, may greatly differ in many phenotypic responses, including biofilm formation, and this variability should be

\section{REFERENCES}

Adams, L. K., Lyon, D. Y., and Alvarez, P. J. J. (2006). Comparative eco-toxicity of nanoscale $\mathrm{TiO}_{2}, \mathrm{SiO}_{2}$, and $\mathrm{ZnO}$ water suspensions. Water Res. 40, 3527-3532. doi: 10.1016/j.watres.2006.08.004

Ansari, M. A., Khan, H. M., Khan, A. A., Cameotra, S. S., Saquib, Q., and Musarrat, J. (2013). Interaction of $\mathrm{Al} 2 \mathrm{O} 3$ nanoparticles with Escherichia always taken into account (Lianou and Koutsoumanis, 2013). This is the reason why in the present study were selected two different strains for each species to form multi-strain biofilm communities. The observed phenotypic variability in biofilm formation which ranges from strong to nonbiofilm formers even at strain level underlies the importance of strain level studies related to survival and spread of bacteria.

\section{CONCLUSION}

To the best of our knowledge, this is the first study evaluating modification of stainless steel and glass surfaces with organosilane based products in order to investigate antiadhesion and anti-biofilm potential against foodborne pathogens. In conclusion, the current study was able to demonstrate antiadhesion and anti-biofilm activity of specific organosilane based products, but this aspect highly depended on the species of pathogens used in this study and time of incubation $(3,24,48$, and $72 \mathrm{~h}$ ). Further studies are needed to establish the underlying mechanisms regarding the role of organosilane based products modification on various surfaces types and bacterial species. On the other hand, nanomaterials could have a fundamental impact on the food and medicine sector, potentially offering benefits as concerning the battle against biofouling.

However, any potential risks for consumers are still required to be estimated and assessed in order to ensure public health. The risk of certain nanomaterial should be evaluated as concern the application, the use and final disposal (Contado, 2015). Furthermore, the risk of consumer exposure to nanoparticles directly from medical implants or indirectly through possible migration from surfaces to foodstuffs should be evaluated, since a knowledge gap exist with regards to absorbance, metabolism, and elimination of nanoparticles from the human body.

\section{AUTHOR CONTRIBUTIONS}

EG designed the studies, performed the experiments, and wrote the paper. $\mathrm{AD}$ designed the studies, performed the experiments, and wrote the paper. NC designed the studies and wrote the paper. G-JN wrote the paper.

\section{ACKNOWLEDGMENT}

EG and AD would like to thank the John S. Latsis Public Benefit Foundation for their financial support.

coli and their cell envelope biomolecules. J. Appl. Microbiol. 116, 772-783. doi: $10.1111 /$ jam. 12423

Araújo, P., Lemos, M., Mergulhão, F., Melo, L., and Simões, M. (2011). "Antimicrobial resistance to disinfectants in biofilms," in Science against Microbial Pathogens: Communicating Current Research and Technological Advances, eds P. Araújo, M. Lemos, F. Mergulhão, L. Melo, and M. Simões (Badajoz: Formatex), 826-834. 
Besinis, A., De Peralta, T., and Handy, R. D. (2014). The antibacterial effects of silver, titanium dioxide and silica dioxide nanoparticles compared to the dental disinfectant chlorhexidine on Streptococcus mutans using a suite of bioassays. Nanotoxicology 8, 1-16. doi: 10.3109/17435390.2012.742935

Bonsaglia, E. C. R., Silva, N. C. C., Fernades, A. Jr., Araújo, J. P. Jr., Tsunemi, M. H., and Rall, V. L. M. (2014). Production of biofilm by Listeria monocytogenes in different materials and temperatures. Food Control 35, 386-391. doi: 10.1016/j. foodcont.2013.07.023

Bos, R., Mei, H. C., Gold, J., and Busscher, H. J. (2000). Retention of bacteria on a substratum surface with micro-patterned hydrophobicity. FEMS Microbiol. Lett. 189, 311-315. doi: 10.1111/j.1574-6968.2000.tb09249.x

Bouwmeester, H., Brandhoff, P., Marvin, H. J. P., Weigel, S., and Peters, R. J. B. (2014). State of the safety assessment and current use of nanomaterials in food and food production. Trends Food Sci. Technol. 40, 200-210. doi: 10.1016/j.tifs. 2014.08.009

Boyce, J. M., Havill, N. L., Guercia, K. A., Schweon, S. J., and Moore, B. A. (2014). Evaluation of two organosilane products for sustained antimicrobial activity on high-touch surfaces in patient rooms. Am. J. Infect. Control 42, 326-328. doi: 10.1016/j.ajic.2013.09.009

Bridier, A., Briandet, R., Thomas, V., and Dubois-Brissonnet, F. (2011). Resistance of bacterial biofilms to disinfectants: a review. Biofouling 27, 1017-1032. doi: 10.1080/08927014.2011.626899

Chen, M., Yu, Q., and Sun, H. (2013). Novel strategies for the prevention and treatment of biofilm related infections. Int. J. Mol. Sci. 14, 18488-18501. doi: 10.3390/ijms140918488

Chorianopoulos, N. G., Tsoukleris, D. S., Panagou, E. Z., Falaras, P., and Nychas, G. E. (2011). Use of titanium dioxide $\left(\mathrm{TiO}_{2}\right)$ photocatalysts as alternative means for Listeria monocytogenes biofilm disinfection in food processing. Food Microbiol. 28, 164-170. doi: 10.1016/j.fm.2010.07.025

Contado, C. (2015). Nanomaterials in consumer products: a challenging analytical problem. Front. Chem. 3:48. doi: 10.3389/fchem.2015.00048

Cousins, B. G., Allison, H. E., Doherty, P. J., Edwards, C., Garvey, M. J., Martin, D. S., et al. (2007). Effects of a nanoparticulate silica substrate on cell attachment of Candida albicans. J. Appl. Microbiol. 102, 757-765. doi: 10.1111/j.1365-2672. 2006.03124.x

da Silva Meira, Q. G., de Medeiros Barbosa, I., Alves Aguiar Athayde, A. J., de Siqueira-Júnior, J. P., and de Souza, E. L. (2012). Influence of temperature and surface kind on biofilm formation by Staphylococcus aureus from foodcontact surfaces and sensitivity to sanitizers. Food Control 25, 469-475. doi: 10.1016/j.foodcont.2011.11.030

Dickson, J. S., and Daniels, E. K. (1991). Attachment of Salmonella typhimurium and Listeria monocytogenes to glass as affected by surface film thickness, cell density, and bacterial motility. J. Ind. Microbiol. 8, 281-283. doi: 10.1007/ BF01576068

Dourou, D., Beauchamp, C. S., Yoon, Y., Geornaras, I., Belk, K. E., Smith, G. C., et al. (2011). Attachment and biofilm formation by Escherichia coli O157:H7 at different temperatures, on various food-contact surfaces encountered in beef processing. Int. J. Food Microbiol. 149, 262-268. doi: 10.1016/j.ijfoodmicro. 2011.07.004

Eginton, P. J., Gibson, H., Holah, J., Handley, P. S., and Gilbert, P. (1995). Quantification of the ease of removal of bacteria from surfaces. J. Ind. Microbiol. 15, 305-310. doi: 10.1007/BF01569984

Finlay, B. B., and Falkow, S. (1997). Common themes in microbial pathogenicity revisited. Microbiol. Mol. Biol. Rev. 61, 136-169.

Giaouris, E., Heir, E., Hébraud, M., Chorianopoulos, N., Langsrud, S., Møretrø, T., et al. (2013). Attachment and biofilm formation by foodborne bacteria in meat processing environments: causes, implications, role of bacterial interactions and control by alternative novel methods. Meat Sci. 97, 298-309. doi: 10.1016/j. meatsci.2013.05.023

Giaouris, E., Heir, E., Hébraud, M., Chorianopoulos, N., Langsrud, S., Møretrø, T., et al. (2014). Attachment and biofilm formation by foodborne bacteria in meat processing environments: causes, implications, role of bacterial interactions and control by alternative novel methods. Meat Sci. 97, 289-309. doi: 10.1016/j. meatsci.2013.05.023

Giaouris, E. D., and Nychas, G. J. E. (2006). The adherence of Salmonella Enteritidis PT4 to stainless steel: the importance of the air-liquid interface and nutrient availability. Food Microbiol. 23, 747-752. doi: 10.1016/j.fm.2006.02.006
Gómez-Suárez, C., Busscher, H. J., and van der Mei, H. C. (2001). Analysis of bacterial detachment from substratum surfaces by the passage of air-liquid interfaces. Appl. Environ. Microbiol. 67, 2531-2537. doi: 10.1128/AEM.67.6. 2531-2537.2001

Götz, F. (2002). Staphylococcus and biofilms. Mol. Microbiol. 43, 1367-1378. doi: 10.1046/j.1365-2958.2002.02827.x

Handford, C. E., Dean, M., Henchion, M., Spence, M., Elliott, C. T., and Campbell, K. (2014). Implications of nanotechnology for the agri-food industry: opportunities, benefits and risks. Trends Food Sci. Technol. 40, 226-241. doi: $10.1016 /$ j.tifs.2014.09.007

Harkes, G., Dankert, J., and Feijen, J. (1992). Growth of uropathogenic Escherichia coli strains at solid surfaces. J. Biomater. Sci. Polym. Ed. 3, 403-418. doi: 10.1163/ 156856292 X00213

Harris, D. L., and Graffagnini, M. J. (2007). Nanomaterials in medical devices: a snapshot of markets, technologies and companies. Nanotechnol. Bus. 255, 415-422.

Heinlaan, M., Ivask, A., Blinova, I., Dubourguier, H. C., and Kahru, A. (2008). Toxicity of nanosized and bulk $\mathrm{ZnO}, \mathrm{CuO}$ and $\mathrm{TiO}_{2}$ to bacteria Vibrio fischeri and crustaceans Daphnia magna and Thamnocephalus platyurus. Chemosphere 71, 1308-1316. doi: 10.1016/j.chemosphere.2007.11.047

Hench, L. L., and West, J. K. (1990). The sol-gel process. Chem. Rev. 90, 33-72. doi: $10.1021 / \mathrm{cr} 00099 \mathrm{a} 003$

Hoyle, B. D., and Costerton, J. W. (1991). Bacterial resistance to antibiotics: the role of biofilms. Prog. Drug Res. 37, 91-105. doi: 10.1007/978-3-0348-7139-6_2

Jena, P., Mohanty, S., Mallick, R., Jacob, B., and Sonawane, A. (2012). Toxicity and antibacterial assessment of chitosan-coated silver nanoparticles on human pathogens and macrophage cells. Int. J. Nanomed. 7, 1805-1818. doi: 10.2147/ IJN.S28077

Joseph, B., Otta, S. K., Karunasagar, I., and Karunasagar, I. (2001). Biofilm formation by Salmonella spp. on food contact surfaces and their sensitivity to sanitizers. Int. J. Food Microbiol. 64, 367-372. doi: 10.1016/S0168-1605(00) 00466-9

Kadam, S. R., den Besten, H. M. W., van der Veen, S., Zwietering, M. H., Moezelaar, R., and Abee, T. (2013). Diversity assessment of Listeria monocytogenes biofilm formation: impact of growth condition, serotype and strain origin. Int. J. Food Microbiol. 165, 259-264. doi: 10.1016/j.ijfoodmicro. 2013.05.025

Kasimanickam, R. K., Ranjan, A., Asokan, G. V., Kasimanickam, V. R., and Kastelic, J. P. (2013). Prevention and treatment of biofilms by hybrid- and nanotechnologies. Int. J. Nanomed. 8, 2809-2819. doi: 10.2147/IJN.S44100

Kim, B., Kim, D., Cho, D., and Cho, S. (2003). Bactericidal effect of $\mathrm{TiO}_{2}$ photocatalyst on selected food-borne pathogenic bacteria. Chemosphere 52, 277-281. doi: 10.1016/S0045-6535(03)00051-1

Kim, T. J., Young, B. M., and Young, G. M. (2008). Effect of flagellar mutations on Yersinia enterocolitica biofilm formation. Appl. Environ. Microbiol. 74, 5466-5474. doi: 10.1128/AEM.00222-08

Kostaki, M., Chorianopoulos, N., Braxou, E., Nychas, G.-J., and Giaouris, E. (2012). Differential biofilm formation and chemical disinfection resistance of sessile cells of Listeria monocytogenes strains under monospecies and dual-species (with Salmonella enterica) conditions. Appl. Environ. Microbiol. 78, 2586-2595. doi: 10.1128/AEM.07099-11

Kregiel, D., and Niedzielska, K. (2014). Effect of plasma processing and organosilane modifications of polyethylene on Aeromonas hydrophila biofilm formation. Biomed Res. Int. 2014:232514. doi: 10.1155/2014/232514

Lafuma, A., and Quéré, D. (2003). Superhydrophobic states. Nat. Mater. 2, 457-460. doi: 10.1038/nmat924

Lianou, A., and Koutsoumanis, K. P. (2013). Strain variability of the behavior of foodborne bacterial pathogens: a review. Int. J. Food Microbiol. 167, 310-321. doi: 10.1016/j.ijfoodmicro.2013.09.016

Lindsay, D., and von Holy, A. (2006). Bacterial biofilms within the clinical setting: what healthcare professionals should know. J. Hosp. Infect. 64, 313-325. doi: 10.1016/j.jhin.2006.06.028

Mittal, K. (2009). Silanes and Other Coupling Agents, Vol. 5. Boca Raton, FL: CRC Press

Morones, J. R., Elechiguerra, J. L., and Camacho, A. (2005). The bactericidal effect of silver nanoparticles. Nanotechnology 16, 2346-2353. doi: 10.1088/0957-4484/ $16 / 10 / 059$ 
Morton, L. H. G., Greenway, D. L. A., Gaylarde, C. C., and Surman, S. B. (1998). Consideration of some implications of the resistance of biofilms to biocides. Int Biodeterior. Biodegrad. 41, 247-259. doi: 10.1016/S0964-8305(98)00026-2

Nørgaard, A. W., Hansen, J. S., Sørli, J. B., Levin, M., Wolkoff, P., Nielsen, G. D., et al. (2014). Pulmonary toxicity of perfluorinated silane-based nanofilm spray products: solvent dependency. Toxicol. Sci. 137, 179-188. doi: 10.1093/toxsci/ $\mathrm{kft} 225$

Oberdörster, G., Oberdörster, E., and Oberdörster, J. (2005). Nanotoxicology: an emerging discipline evolving from studies of ultrafine particles. Environ. Health Perspect. 113, 823-839. doi: 10.1289/ehp.7339

Oniciuc, E.-A., Cerca, N., and Nicolau, A. I. (2016). Compositional analysis of biofilms formed by Staphylococcus aureus isolated from food sources. Front. Microbiol. 7:390. doi: 10.3389/fmicb.2016.00390

Pereni, C. I., Zhao, Q., Liu, Y., and Abel, E. (2006). Surface free energy effect on bacterial retention. Colloids Surf. B Biointerfaces 48, 143-147. doi: 10.1016/j. colsurfb.2006.02.004

Prigent-Combaret, C., Vidal, O., Dorel, C., and Lejeune, P. (1999). Abiotic surface sensing and biofilm-dependent regulation of gene expression in Escherichia coli. J. Bacteriol. 181, 5993-6002.

Privett, B. J., Youn, J., Hong, S. A., Lee, J., Han, J., Shin, J. H., et al. (2011). Antibacterial fluorinated silica colloid superhydrophobic surfaces. Langmuir 27, 9597-9601. doi: 10.1021/la201801e

Reid, G., Lam, D., Policova, Z., and Neumann, A. W. (1993). Adhesion of two uropathogens to silicone and lubricious catheters: influence of $\mathrm{pH}$, urea and creatinine. J. Mater. Sci. Mater. Med. 4, 17-22. doi: 10.1007/BF0012 2972

Robert, J. M. I., Toguchi, A., and Harshey, R. M. (2001). Salmonella enterica serovar typhimurium swarming mutants with altered biofilm-forming abilities: surfactin inhibits biofilm formation Salmonella enterica serovar typhimurium swarming mutants with altered biofilm-forming abilities: surfactin inhibits bio. J. Bacteriol. 83, 5848-5854. doi: 10.1128/JB.183.20.5848

Schmidt, H. (2006). Considerations about the sol-gel process: from the classical sol-gel route to advanced chemical nanotechnologies. J. Sol Gel Sci. Technol. 40, 115-130. doi: 10.1007/s10971-006-9322-6

Sepeur, S. (2008). Nanotechnology: Technical Basis and Applications. Hanover: Vincentz Network.
Song, J., Kong, H., and Jang, J. (2011). Bacterial adhesion inhibition of the quaternary ammonium functionalized silica nanoparticles. Colloids Surf. B Biointerfaces 82, 651-656. doi: 10.1016/j.colsurfb.2010.10.027

Stepanović, S., Cirković, I., Ranin, L., and Svabić-Vlahović, M. (2004). Biofilm formation by Salmonella spp. and Listeria monocytogenes on plastic surface. Lett. Appl. Microbiol. 38, 428-432. doi: 10.1111/j.1472-765X.2004.01513.x

Stepanović, S., Vuković, D., Dakić, I., Savić, B., and Švabić-Vlahović, M. (2000). A modified microtiter-plate test for quantification of staphylococcal biofilm formation. J. Microbiol. Methods 40, 175-179. doi: 10.1016/S0167-7012(00) 00122-6

Teixeira, P., Silva, S. C., Araújo, F., Azeredo, J., and Oliveira, R. (2007). "Bacterial adhesion to food contacting surfaces," in Communicating Current Research and Educational Topics and Trends in Applied Microbiology, ed. A. Mendez-Vilas (Badajoz: Formatex Research Center), 13-20.

Thames, S. F., and Panjnani, K. G. (1996). Organosilane polymer chemistry: a review. J. Inorg. Organomet. Polym. 6, 59-94. doi: 10.1007/BF01098320

van Loosdrecht, M. C., Lyklema, J., Norde, W., Schraa, G., and Zehnder, A. J. (1987). Electrophoretic mobility and hydrophobicity as a measured to predict the initial steps of bacterial adhesion. Appl. Environ. Microbiol. 53, 1898-1901. doi: $10.1007 / \mathrm{BF} 00878244$

Conflict of Interest Statement: The authors declare that the research was conducted in the absence of any commercial or financial relationships that could be construed as a potential conflict of interest.

The reviewer Dr. AC and handling Editor declared their shared affiliation, and the handling Editor states that the process neverthless met the standards of a fair and objective review.

Copyright (C) 2017 Gkana, Doulgeraki, Chorianopoulos and Nychas. This is an openaccess article distributed under the terms of the Creative Commons Attribution License (CC BY). The use, distribution or reproduction in other forums is permitted, provided the original author(s) or licensor are credited and that the original publication in this journal is cited, in accordance with accepted academic practice. No use, distribution or reproduction is permitted which does not comply with these terms. 